\title{
Mapeamento ergonômico da função eletricista, na Companhia Paranaense de Energia - COPEL, Divisão de Manutenção Norte
}

\author{
Ergonomic mapping of the "electrician" function, in Companhia \\ Paranaense de Energia - COPEL, Northern Maintenance Division
}

\section{CIOTTA, Daniele}

Universidade Tecnológica Federal do Paraná - UTFPR I dani_ciotta@hotmail.com

SILVA, André Luís da

Universidade Tecnológica Federal do Paraná - UTFPR I andrels@utfpr.edu.br

\begin{abstract}
Resumo
Este estudo apresenta um mapeamento ergonômico das condições de trabalho de eletricistas da Companhia Paranaense de Energia - COPEL. Para tal fim, aplicou-se a etnografia como método de pesquisa e o questionário nórdico como técnica complementar. Os resultados demonstraram relação entre a predominância de sintomatologia dolorosa e as tarefas exercidas por estes profissionais, indicando à empresa a necessidade da adoção de ações e programas preventivos concernentes à ergonomia dos trabalhadores.

\section{Abstract}

This study presents an ergonomic mapping of the working conditions of electricians at the Companhia Paranaense de Energia - COPEL. With this purpose, the ethnography was applied as the research method and the Nordic questionnaire was used as a complementary technique. Results showed a relationship between the predominance of pain symptomatology and the tasks performed by these professionals, indicating to the company the need to adopt preventive actions and programs concerning the ergonomics of workers.
\end{abstract}

Palavras-chave: osteomusculares. Ergonomia. Distúrbios trabalho.
Keywords: Ergonomics. Musculoskeletal disorders. Electrician. Working posture. 


\section{INTRODUC̣ÃO}

Em razão da importância da energia elétrica para a sociedade, o segmento distribuição, responsável pela entrega do produto ao usuário final e por garantir a confiabilidade do sistema, constitui-se essencial para a concessionária de energia. Entretanto, a qualidade deste serviço não depende apenas de equipamentos e procedimentos, mas, também do elemento humano, através do profissional eletricista.

Embora o risco de acidentes com consequentes lesões por exposição a eletricidade seja iminente para a função eletricista, distúrbios osteomusculares e doenças relacionados ao trabalho também se fazem presentes, por estarem expostos a condições ergonômicas desfavoráveis, como exigência de posturas inadequadas, esforço físico intenso e levantamento e transporte de peso.

Assim, por tratar-se de uma função indispensável para a empresa e que vem apresentando, ao longo dos anos, uma incidência considerável de distúrbios osteomusculares relacionados ao trabalho, faz-se necessária e importante uma abordagem mais atenta às peculiaridades da profissão, no que tange os riscos ergonômicos susceptíveis de ameaçar a saúde e a integridade física dos trabalhadores expostos.

A Copel Distribuição S/A possui em seu quadro funcional, um total de aproximadamente 1598 eletricistas, atuando em diversas áreas da empresa, em todo o Estado.

Este trabalho teve como objetivo mapear a função eletricista de manutenção de linhas e redes de distribuição, visando apurar as principais causas da redução da capacidade de trabalho, os problemas ergonômicos presentes na execução das atividades rotineiras e as inadequações referentes aos equipamentos e materiais utilizados para a realização dos serviços.

Nessa acepção, definidos o público alvo e a questão a ser estudada, empregou-se a etnografia como método de pesquisa, contemplando a observação participante, com registros fotográficos e tomada de apontamentos.

Os resultados alcançados indicaram alta predominância de sintomas musculoesqueléticos entre os eletricistas, associados às atividades por eles desempenhadas, sinalizando risco de evolução para DORT no futuro e a necessidade da adoção de ações, medidas e programas preventivos que visem contribuir para a adaptação ou transformação das condições de trabalho, de modo a favorecer a saúde e o bem-estar dos colaboradores, implicando na melhoria de qualidade e produtividade para a empresa e maior satisfação dos empregados. 


\section{POSTURA DE TRABALHO}

O trabalho realizado por lida (2005), conceitua postura como o estudo do posicionamento das partes do corpo no espaço.

Ao desempenhar qualquer atividade, o indivíduo assume várias posturas, de acordo com as necessidades de força, velocidade e precisão de movimentos que compõem cada tarefa. Durante a jornada de trabalho, adota posturas distintas que, muitas vezes, se mantém por longos períodos. As variações posturais sofrem influência de fatores externos (atividade e condições em que será desempenhada) e internos individuais, como: características antropométricas, estado funcional, físico-sensorial, experiência, entre outros (AGUIAR, 1996).

A melhor postura é aquela que o trabalhador escolhe livremente e que pode ser variada ao longo da jornada. As consequências prejudiciais de uma determinada postura dependem do período em que esta será mantida, portanto, o seu tempo de duração deve ser o menor possível. A concepção dos postos de trabalho e das atividades deve favorecer a alternância de postura (BRASIL, 2002).

A flexibilidade postural, que favorece a variação das posturas corporais pelo sistema musculoesquelético, revezando os pontos principais de exigência e permitindo mobilidade, constitui-se regra essencial da ergonomia e da manutenção da saúde de músculos, tendões, etc. (RIO; PIRES, 2001).

Por vezes, os trabalhadores adotam posturas inadequadas, em função das exigências da tarefa ou projetos deficientes de equipamentos e postos de trabalho. A má postura pode desencadear efeitos danosos em três situações principais: trabalhos estáticos por longo período, trabalhos que demandam muita força e os que requerem posturas desfavoráveis (IIDA, 2005).

Segundo Aguiar (1996), pode-se considerar uma postura incorreta quando esta for ineficaz no atendimento ao objetivo pretendido, exigir gasto energético e esforço muscular demasiado para ser mantida, oferecer risco à segurança do trabalhador ou às estruturas musculoesqueléticas envolvidas na atividade.

De acordo com o tipo de trabalho muscular, Kroemer e Grandjean (2005) classificam a postura de duas formas: dinâmica (variação) e estática (manutenção). 


\section{DOENC̣AS RELACIONADAS AO TRABALHO}

Trata-se de um conjunto de danos ou agravos que incorrem sobre a saúde dos trabalhadores, provocados, desencadeados ou agravados por fatores de risco existentes no ambiente laboral, de forma que os sintomas se manifestam lenta e insidiosamente (BRASIL, 2002).

As denominações oficiais do Ministério da Saúde e da Previdência Social para os agravos relativos ao trabalho são grafadas como LER/DORT lesões por esforços repetitivos/distúrbios osteomusculares relacionados ao trabalho. Constituem-se danos resultantes da utilização em excesso, imposta ao sistema musculoesquelético e da falta de tempo para recuperação. A elevada predominância dessas doenças tem sido associada às transformações do trabalho e das empresas (BRASIL, 2012).

Os reveses oriundos das LER/DORT afetam diversas áreas da empresa, tanto em relação à da produtividade quanto à elevação dos custos: absenteísmo; retreinamento; aumento do custo de produção; gastos com tratamento médico; afastamentos prolongados; custos com reintegração de operários e processos indenizatórios de responsabilidade civil (COUTO, 2007).

As doenças do sistema musculoesquelético e as psicológicas predominam como mais significativa causa de absenteísmo e de incapacitação ao trabalho. Pode-se atribuir estas ocorrências ao mau projeto e utilização incorreta de equipamentos, sistemas e tarefas. A ergonomia pode cooperar para a redução desses problemas (DUL; WEERDMEESTER, 2004).

O surgimento de LER/DORT não se dá por uma causa única. Diversos são os fatores presentes no trabalho que podem concorrer para o seu desencadeamento, como: movimentos repetitivos, posturas inadequadas mantidas por tempo prolongado, esforço físico, invariabilidade de tarefas, pressão mecânica sobre partes do corpo, trabalho estático, choques e impactos, vibração, aspectos organizacionais e psicossociais (BRASIL, 2000).

\section{ELETRICISTA}

O trabalho com eletricidade representa alto risco para os profissionais atuantes na área, pela susceptibilidade à ocorrência de acidentes graves e fatais (GUIMARÃES et al., 2002). Entretanto, Castro (2011) ressalta que também estão expostos a riscos ergonômicos, de ordem biomecânica, associados ao desenvolvimento de DORT.

Poucos eletricistas apresentam capacidade física para exercer a função durante toda a vida laboral, pois muitos destes profissionais são acometidos de 
lesões musculoesqueléticas, após anos de exposição, essencialmente pelo uso excessivo da força (SEELEY; MARKLIN, 2003).

Contudo, apesar das condições ergonômicas críticas presentes na atividade, a predominância de sintomas musculoesqueléticos em eletricistas do setor de distribuição de energia elétrica brasileiro, bem como a descrição dos principais fatores de risco biomecânicos associados ao seu trabalho, ainda não foram estudados pela literatura existente (CASTRO, 2011).

\section{METODOLOGIA}

Considerando-se que este estudo buscou explorar e identificar os problemas ergonômicos vivenciados por um grupo específico de trabalhadores, aspirando compreender seus comportamentos, experiências, técnicas e práticas na execução das atividades diárias, optou-se pela adoção do método de pesquisa etnográfico.

Moreira e Caleffe (2006) entendem que a investigação etnográfica engloba algumas etapas que facilitam o desenvolvimento da investigação, como: elaborar uma questão relevante a ser pesquisada, identificar um grupo para estuda-la, inserir a proposta de incursão ao grupo para obter seu consentimento e envolvimento. A coleta de dados se dá a partir da observação participante e contextualizada e de anotações realizadas em campo, para posterior descrição detalhada, que auxilia na compreensão do problema pesquisado, admitindo, inclusive, o uso de técnicas complementares (entrevistas, narrativas, história de vida, etc).

Inicialmente, aplicou-se um questionário a 37 dos 46 eletricistas de manutenção de linhas e redes de distribuição, que compõem a Divisão de Manutenção Norte, em maio de 2016, durante as reuniões setoriais de segurança, realizadas pelos setores de manutenção de Londrina, Apucarana e Cornélio Procópio.

O questionário apresentou perguntas gerais para coleta de dados demográficos (idade, sexo, altura, peso, etc.) e ocupacionais (tempo de serviço na empresa, horário de trabalho, etc.), além de indagações sobre saúde geral e nível de atividade física. Também solicitou-se ao trabalhador identificar a ocorrência de sintomas em nove regiões anatômicas, utilizandose o Questionário Nórdico Padronizado ou Nordic Musculoskeletal Questionnaire (NMQ), a partir de uma versão em português traduzida por Barros e Alexandre (2003), considerando os doze meses e os sete dias precedentes à entrevista e os afastamentos das atividades no último ano. 
Figura 1 - Nordic Musculoskeletal Questionnaire (NMQ).

\begin{tabular}{|c|c|c|c|c|c|c|c|c|}
\hline \multirow[b]{2}{*}{ PESCOÇO } & \multicolumn{2}{|c|}{$\begin{array}{l}\text { Nos últimos } 12 \\
\text { meses, vooé teve } \\
\text { problemas (como } \\
\text { dor, formigamento/ } \\
\text { dorméncia) em: }\end{array}$} & \multicolumn{2}{|c|}{$\begin{array}{l}\text { Nos úttimos } 12 \text { meses, } \\
\text { voce foi impedido(a) de } \\
\text { realizar atividades } \\
\text { normais (por exemplo: } \\
\text { trababaho, atividades } \\
\text { domésticas e de lazer) } \\
\text { por causa desse } \\
\text { problema em: }\end{array}$} & \multicolumn{2}{|c|}{$\begin{array}{l}\text { Nos últimos } 12 \\
\text { meses, vocé } \\
\text { consultou algum } \\
\text { profissional da área } \\
\text { da saúde (médico, } \\
\text { fisioterapeuta) por } \\
\text { causa dessa } \\
\text { condiçåa em: }\end{array}$} & \multicolumn{2}{|c|}{$\begin{array}{c}\text { Nos últimos } 7 \\
\text { dias, voce teve } \\
\text { algum problema } \\
\text { em? }\end{array}$} \\
\hline & $\square$ Não & $\square \mathrm{Sim}$ & $\square$ Nầo & $\square \operatorname{sim}$ & $\square$ Nâo & $\square \mathrm{sim}$ & $\square$ Nầo & $\square \operatorname{sim}$ \\
\hline -MBRROS & $\square$ Não & $\square \mathrm{sim}$ & $\square$ Nầo & $\square \operatorname{sim}$ & $\square$ Não & $\square \mathrm{sim}$ & $\square$ Năo & $\square \operatorname{sim}$ \\
\hline $\begin{array}{l}\text { PARTE SUPERIOR } \\
\text { DAS COSTAS }\end{array}$ & $\square$ Nằ & $\square \operatorname{sim}$ & $\square$ Nåo & $\square \mathrm{sim}$ & $\square$ Não & $\square \mathrm{sim}$ & $\square$ Nåo & $\square \operatorname{sim}$ \\
\hline еOTOVELOS & $\square$ Não & $\square \mathrm{sim}$ & $\square$ Năo & $\square \operatorname{sim}$ & $\square$ Não & $\square \operatorname{sim}$ & $\square$ Năo & $\square \operatorname{sim}$ \\
\hline PUNHOSMMĀOS & $\square$ Năo & $\square \mathrm{sim}$ & $\square$ Nåo & $\square \operatorname{sim}$ & $\square$ Năo & $\square \mathrm{sim}$ & $\square$ Não & $\square \operatorname{sim}$ \\
\hline $\begin{array}{l}\text { RARTE INFERIOR } \\
\text { DAS COSTAS }\end{array}$ & $\square$ Não & $\square \mathrm{sim}$ & $\square$ Nåo & $\square \mathrm{sim}$ & $\square$ Não & $\square \operatorname{sim}$ & $\square$ Não & $\square \operatorname{sim}$ \\
\hline QUADRIL/COXAS & $\square$ Não & $\square \mathrm{sim}$ & $\square$ Nåo & $\square \operatorname{sim}$ & $\square$ Năo & $\square \operatorname{sim}$ & $\square$ Năo & $\square \mathrm{sim}$ \\
\hline JOELHOS & $\square$ Năo & $\square \operatorname{sim}$ & $\square$ Nåo & $\square \operatorname{sim}$ & $\square$ Não & $\square \mathrm{sim}$ & $\square$ Năo & $\square \operatorname{sim}$ \\
\hline $\begin{array}{l}\text { TORNOZELOS/ } \\
\text { PES }\end{array}$ & $\square$ Nâo & $\square \mathrm{sim}$ & $\square$ Nấo & $\square \operatorname{sim}$ & $\square$ Não & $\square \mathrm{sim}$ & $\square$ Năo & $\square \mathrm{sim}$ \\
\hline
\end{tabular}

Fonte: Barros e Alexandre (2003).

Por fim, questões abertas e de múltipla escolha buscaram verificar a existência ou não de relação entre a sintomatologia dolorosa e o trabalho exercido, bem como, de desconforto e dificuldades no manuseio do ferramental utilizado.

Conforme estabelece a metodologia escolhida, procedeu-se o acompanhamento in loco (desde 2015) do trabalho dos eletricistas, em área rural e urbana, em período diurno, em condições climáticas normais e adversas, com a finalidade de conhecer o método de execução de suas atividades diárias, em solo e plano elevado (postes), as principais dificuldades físicas, além das ferramentas e materiais utilizados na realização dos serviços.

Foram coletadas imagens fotográficas dos trabalhadores atuando na prática de suas atividades diárias, com o intuito de registrar e analisar as posturas adotadas pelos eletricistas durante a execução dos serviços, sendo selecionadas para integrar esta pesquisa, algumas tarefas e ferramentais considerados pelos eletricistas no questionário como críticos, que oferecem maior dificuldade e desconforto.

O peso dos materiais utilizados com maior frequência foi constatado por meio de dinamômetro ou apurado junto ao fabricante.

\section{RESULTADOS}

\subsection{Aplicação de Questionário}

Quando analisadas as queixas de dor e desconforto, observou-se que os primeiros sintomas começam a surgir ainda nos primeiros 5 anos de trabalho na função. Apenas um eletricista desse grupo, ou seja, o equivalente a 
2,7\% do total de participantes da pesquisa, declarou não apresentar nenhuma sintomatologia dolorosa. Após esse período, isto é, a partir de 6 anos de atividade laboral, $100 \%$ dos entrevistados relataram queixas de dor.

Com a aplicação do questionário nórdico aos eletricistas da Copel, pode-se determinar a topografia da dor e desconforto entre os envolvidos, conhecendo-se as partes do corpo de maior acometimento. As regiões sintomáticas mais citadas pelos eletricistas na pesquisa (podendo-se apontar mais de uma) foram: ombros, parte inferior das costas e joelhos, somando juntas, $56 \%$ da localização total das queixas.

Grande parte das atividades dos eletricistas são executadas com uso de força e posturas inadequadas, como manutenção dos membros superiores acima do nível dos ombros, etc. Esses fatores de risco podem justificar a elevada predominância de sintomatologia musculoesquelética nos ombros (ALENCAR, 2008).

Ao responderem se nos últimos 12 meses tiveram problemas (como dor, formigamento/dormência) nas regiões anatômicas consideradas, os empregados realizaram 118 apontamentos, revelando a topografia dos sintomas, cuja maior predominância incide sobre os ombros (22,7\%), seguida da parte inferior das costas $(17,3 \%)$ e joelhos $(13,6 \%)$.

Os eletricistas que, nos últimos 12 meses, disseram ter sido impedidos de realizar atividades normais (por exemplo: trabalho, atividades domésticas e lazer) por problemas físicos, indicaram as zonas corporais mais comprometidas. Foram efetuadas 34 indicações, de modo que a parte inferior das costas foi a região mais apontada (23,5\%), seguida dos ombros e joelhos, com incidência de $20,6 \%$ cada. Problemas nos tornozelos/pés não foram citados como origem de impedimento por nenhum dos entrevistados.

De acordo com as respostas dos eletricistas, que juntos realizaram 51 menções às partes do corpo que mais motivaram consultas a profissionais da área da saúde (médico, fisioterapeuta) nos últimos 12 meses, verifica-se que $43,2 \%$ das consultas foram originadas por problemas nos ombros e joelhos. Em ordem subsequente, aparece a parte inferior das costas, com 17,6\%.

As motivações das consultas são coerentes com as queixas apresentadas pelos empregados, uma vez que, em resposta às indagações anteriores, presentes no questionário nórdico, as regiões do ombro, joelho e parte inferior das costas foram as que mais sobressaíram, sendo observadas apenas alterações na ordem de incidência.

Também foram indagados se, nos sete dias antecedentes à entrevista, apresentaram algum problema nas áreas do corpo indicadas no NQM. O resultado obtido, composto por 33 apontamentos, evidencia maior quantidade 
de ocorrências nos ombros (27,2\%), precedida de joelhos e cotovelos (15,2\% de incidência cada).

Do total de eletricistas da empresa que mencionaram alguma queixa de dor ou desconforto, $47 \%$ afirmam que as dores se iniciam após o trabalho, $25 \%$ durante o trabalho, $20 \%$ sentem-nas o dia todo e $8 \%$ disseram que as dores começam durante o sono, sendo possível senti-las ao acordarem. Dos empregados que apresentaram sintomatologia dolorosa, $89 \%$ declaram que as dores têm relação com o trabalho e 11\% não souberam responder a indagação. A maioria destes eletricistas (94\%) afirmam não ter sentido dores em trabalho anterior a este. Portanto, os outros $6 \%$ já apresentavam sintomatologia dolorosa antes de exercerem a atual atividade.

A pesquisa denotou que $51 \%$ da amostra de empregados participantes já necessitaram afastar-se do trabalho por problemas físicos (relacionados ao trabalho ou não), em algum momento da vida laboral, o que equivale a 19 eletricistas.

O absenteísmo relatado totalizou 1581 dias (média de 83,2 dias/ empregado afastado), por motivos diversos, sendo que, cirurgia de joelho, hérnia de disco e cirurgia de ombro originaram o afastamento de 3 empregados cada ( 9 trabalhadores no total), gerando 1300 dias ou 82,2\% das ausências no trabalho.

Quanto às maiores dificuldades ergonômicas para a execução das tarefas na Copel, entre as opções de respostas disponibilizadas no questionário, podendo-se assinalar mais de uma, conforme a percepção dos envolvidos, o fator de risco mais citado foi o esforço físico intenso, com 37\% das indicações. Em seguida, estão postura inadequada (29\%) e levantamento e transporte de peso $(25 \%)$.

Os eletricistas também especificaram outras situações críticas (9\%), como: trabalho com peso acima da altura da cabeça, falta de ginástica laboral na empresa, altura da vara de manobra, condições climáticas intensas, agachar e levantar diversas vezes ao dia, excesso de tarefas, andar em terreno irregular e esforço repetitivo de membros superiores.

Questionados se há alguma tarefa específica que lhes causa maior dor ou desconforto, $81 \%$ dos eletricistas responderam afirmativamente à pergunta. Tratando-se de questão aberta, os participantes elencaram 17 atividades (citadas 32 vezes), as quais consideraram influenciar nos sintomas físicos já constatados, entre elas: transportar transformador/poste de fibra (18,7\%), escalar/permanecer com esporas no poste, instalar aterramento temporário e levantar peso ( $9,4 \%$ cada). 
O questionário aplicado buscou saber se os entrevistados têm dificuldades, dor ou desconforto no manuseio dos equipamentos de trabalho, de maneira que, 21 deles (56,7\% da amostra) responderam de modo afirmativo. A pergunta aberta possibilitou que os empregados pudessem relacionar 9 equipamentos, mencionados 27 vezes, sendo mais citados: aterramento temporário (25,9\%), vara/bastão (18,5\%), esporas e motosserra/motopoda (14,8\% cada).

Concernente às principais dificuldades com relação aos equipamentos utilizados na execução das atividades, entre as alternativas de resposta presentes no questionário (havendo a possibilidade de mais de uma escolha), as de maior incidência foram: a postura necessária para o uso (33\%), o peso (29\%) e o tempo de uso durante o serviço (20\%).

Ao serem indagados se praticam ou não alguma atividade física, 59,4\% (22 eletricistas) responderam que sim. Quanto à frequência com que se dá esta prática, a maioria se exercita de vez em quando (32\%) ou, no máximo, duas vezes por semana (32\%).

\subsection{Acompanhamento de Atividades em Campo}

A postura de trabalho em cima do poste, em pé, implica em posição estática da musculatura dos membros inferiores, sendo fonte de desconforto e dor. Apresenta problemas de acomodação dos membros inferiores, devido às peculiaridades da tarefa a ser realizada, ao arranjo dos elementos que compõem a rede elétrica e suas estruturas e aos métodos de escalada e posicionamento com esporas e escadas.

Os eletricistas buscam a posição semissentada para a execução de serviços nos postes. O talabarte, componente do conjunto antiqueda para trabalho em altura, é posicionado nos quadris. O cinto paraquedista utilizado, é almofadado também na altura do quadril. Ambos servem de apoio para a posição semissentada.

Durante a realização dos trabalhos, são adotadas posturas desfavoráveis e desconfortáveis, incluindo abdução de braços, flexão do pescoço e desvio de tronco.

O eletricista, no exercício de suas atividades em plano elevado, necessita manusear, levantar e sustentar equipamentos, como: esporas nos pés, vara telescópica, bastão de manobra, aterramento temporário, detector de tensão, entre outros. Essa condição representa um esforço físico considerável, com variação nas posturas de rotação e extensão de tronco, membros superiores e inferiores. 


\subsubsection{Posição estática de membros inferiores}

O trabalho estático caracteriza-se por exigir a contração contínua de músculos, a fim de manter determinada posição. É extremamente fatigante, devendo ser evitado, sempre que possível, ou aliviado com mudança de posturas, melhor posicionamento de ferramentas ou utilização de apoios para as partes do corpo. Na posição parada, em pé, o coração encontra maior dificuldade para bombear sangue para as extremidades do corpo, desencadeando a fadiga dos músculos (IIDA, 2005).

A Figura 2 ilustra a espora, equipamento utilizado para escalada em poste.

Figura 2 - Espora tipo D para escalada em poste.
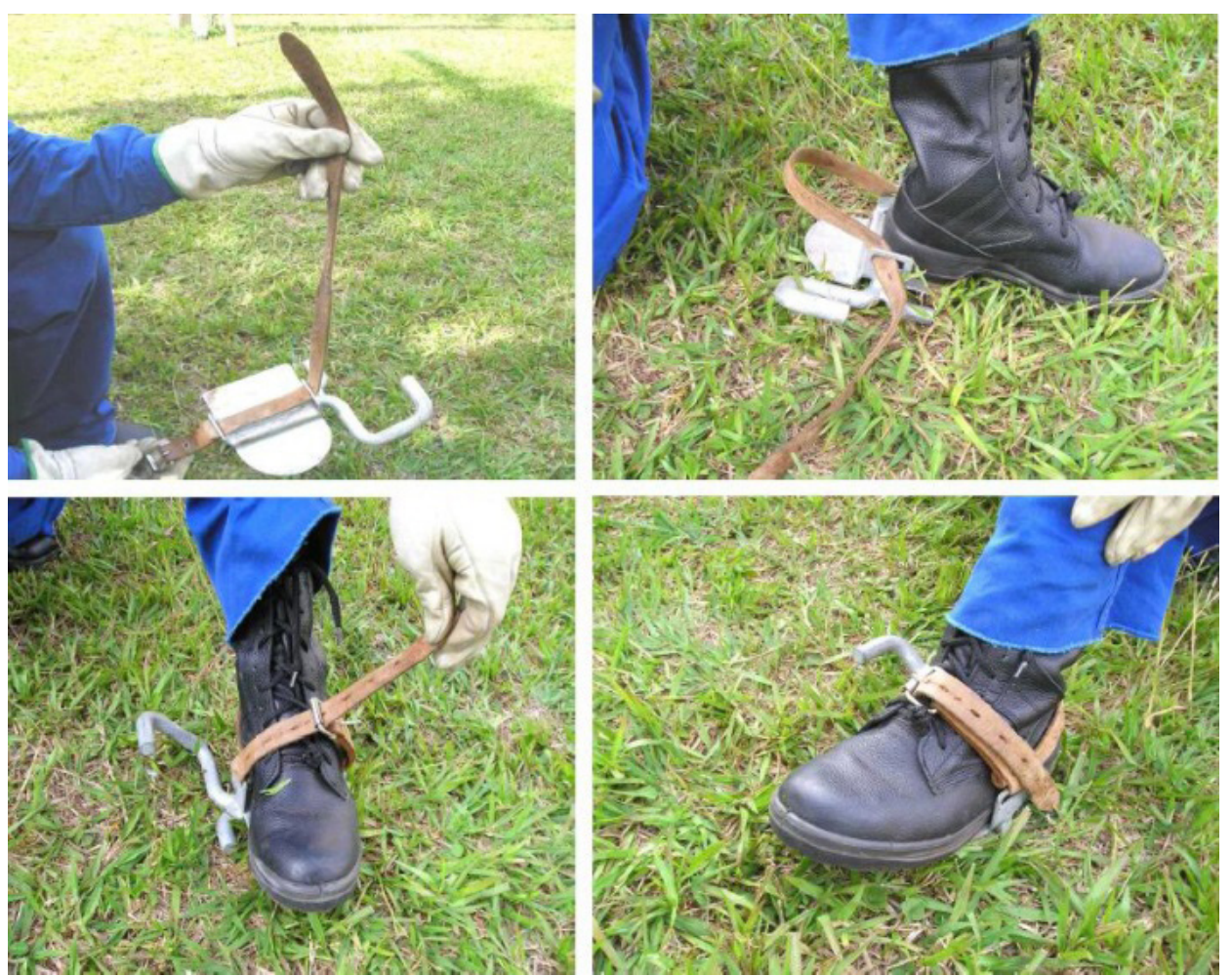

Fonte: COPEL (2013).

A Figura 3 mostra o eletricista executando trabalho em plano elevado, em posição estática, utilizando esporas nos pés. 
Figura 3 - Posição estática do eletricista em cima do poste.

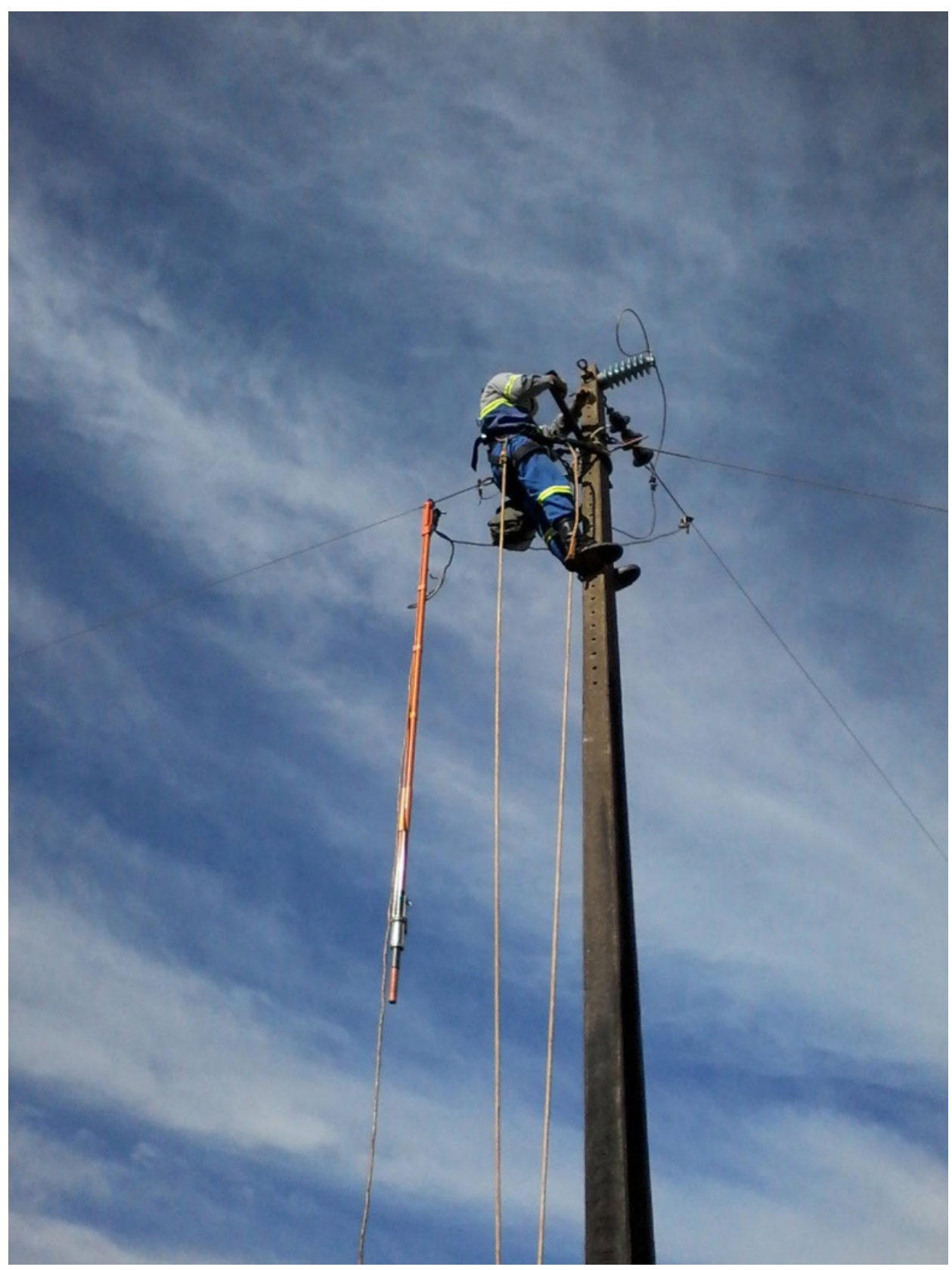

Fonte: COPEL (2013).

Um eletricista de manutenção de linhas e redes chega a permanecer em cima do poste, por um período médio de até 3 horas, sem interrupção, dependendo da atividade a ser executada, utilizando as esporas nos pés, cujo peso aproximado é de $2,5 \mathrm{~kg}$ (par), sendo o terceiro equipamento mais apontado pelos usuários como causador de dor e desconforto (14,8\%), no questionário aplicado em uma das etapas da pesquisa.

Obrigatoriamente, o profissional também deve estar munido de conjunto para trabalho em altura, composto por cinto paraquedista, talabarte de posicionamento e trava quedas, agregando ao corpo um peso adicional de 6 $\mathrm{kg}$. 


\subsubsection{Torção de Tronco}

Considerando que este é o segmento mais importante para a estabilidade do corpo, muitos movimentos solicitam a ativação postural dos músculos do tronco. Se, durante a atividade laborativa, o trabalhador usá-lo em excesso ou de maneira incorreta, em tarefas repetitivas, pode incutir uma sobrecarga inadequada sobre os elementos musculoesqueléticos da região, especialmente na coluna vertebral (ENOKA, 2000).

A torção do tronco causa maior tensão entre os discos intervertebrais, sendo que, as articulações e os músculos responsáveis por esse movimento são submetidos a cargas assimétricas que são prejudiciais (DUL; WEERDMEESTER, 2004).

A Figura 4 exemplifica uma das tarefas em que o eletricista necessita executar torção estática de tronco, para de instalação de aterramento temporário de média tensão.

Figura 4 - Torção estática de tronco do eletricista.

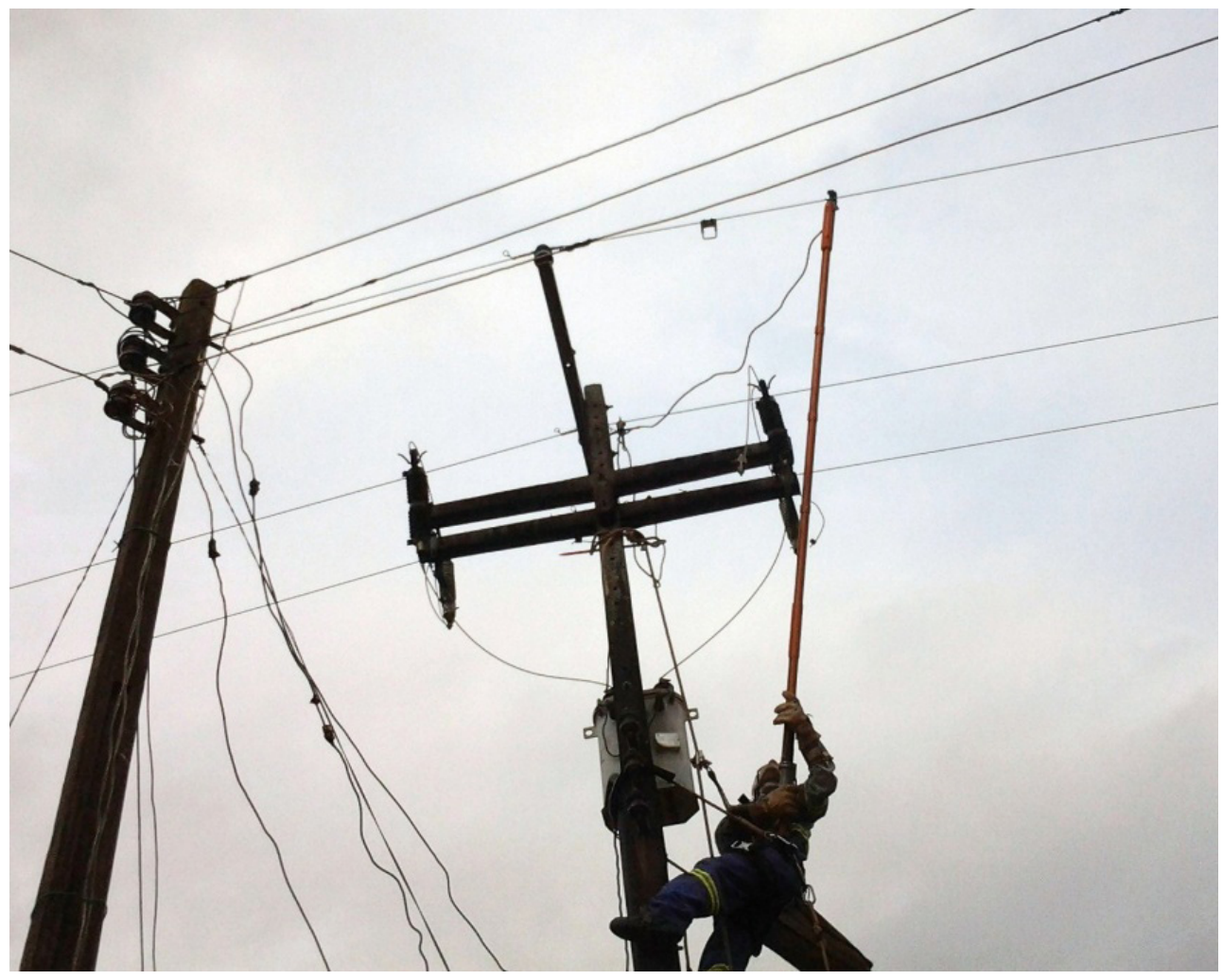

Fonte: COPEL (2013).

O profissional utiliza um bastão de manobra de aproximadamente 4,5 $\mathrm{kg}$ para içar e instalar o conjunto de aterramento que pesa em torno de $20 \mathrm{~kg}$ e foi considerado o equipamento que mais provoca desconforto e dor $(25,9 \%)$, de acordo com as respostas dos entrevistados ao questionário aplicado. 
Os componentes do aterramento que necessitam ser içados pelo eletricista são: um trapézio de alumínio, de suspensão para elevação simultânea dos grampos das fases; quatro grampos com parafuso em bronze, corpo de alumínio; cabo de cobre extra flexível, sendo 2 lances de 2 m e 1 lance de 12 m.

A Figura 5 ilustra os componentes do conjunto de aterramento temporário tipo sela, utilizado pelos eletricistas.

Figura 5 - Conjunto de Aterramento Temporário de Média Tensão Tipo Sela.

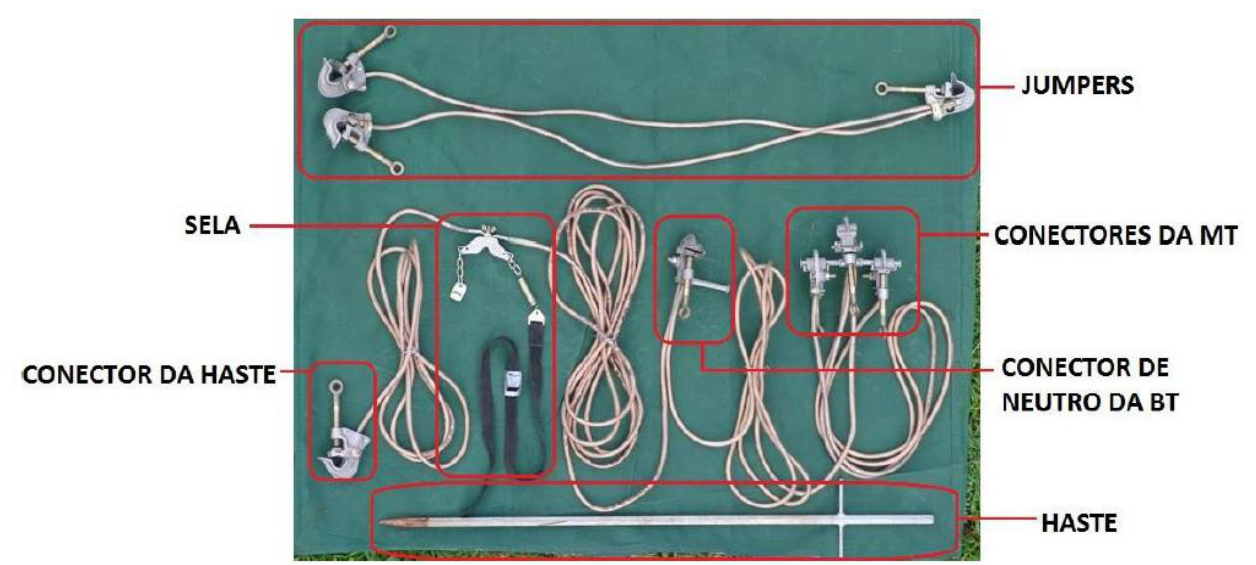

Fonte: COPEL (2015).

\subsubsection{Inclinação da Cabeça}

Trata-se de postura desfavorável biomecanicamente, que provoca rápida fadiga nos músculos do pescoço e do ombro, devido peso relativamente elevado da cabeça, entre 4 e 5 quilos (FALCÃO, 2007).

Quando a cabeça é flexionada mais de 30o, os músculos do pescoço tencionam-se para manter a postura, o que provoca sobrecarga no pescoço e ombros. Recomenda-se manter a cabeça o mais próximo possível da posição vertical (MATTOS; MÁSCULO, 2011).

A Figura 6 demonstra a necessidade do eletricista de curvar a cabeça para trás, para instalar o aterramento temporário. 
Figura 6 - Inclinação (para trás) da cabeça do eletricista.

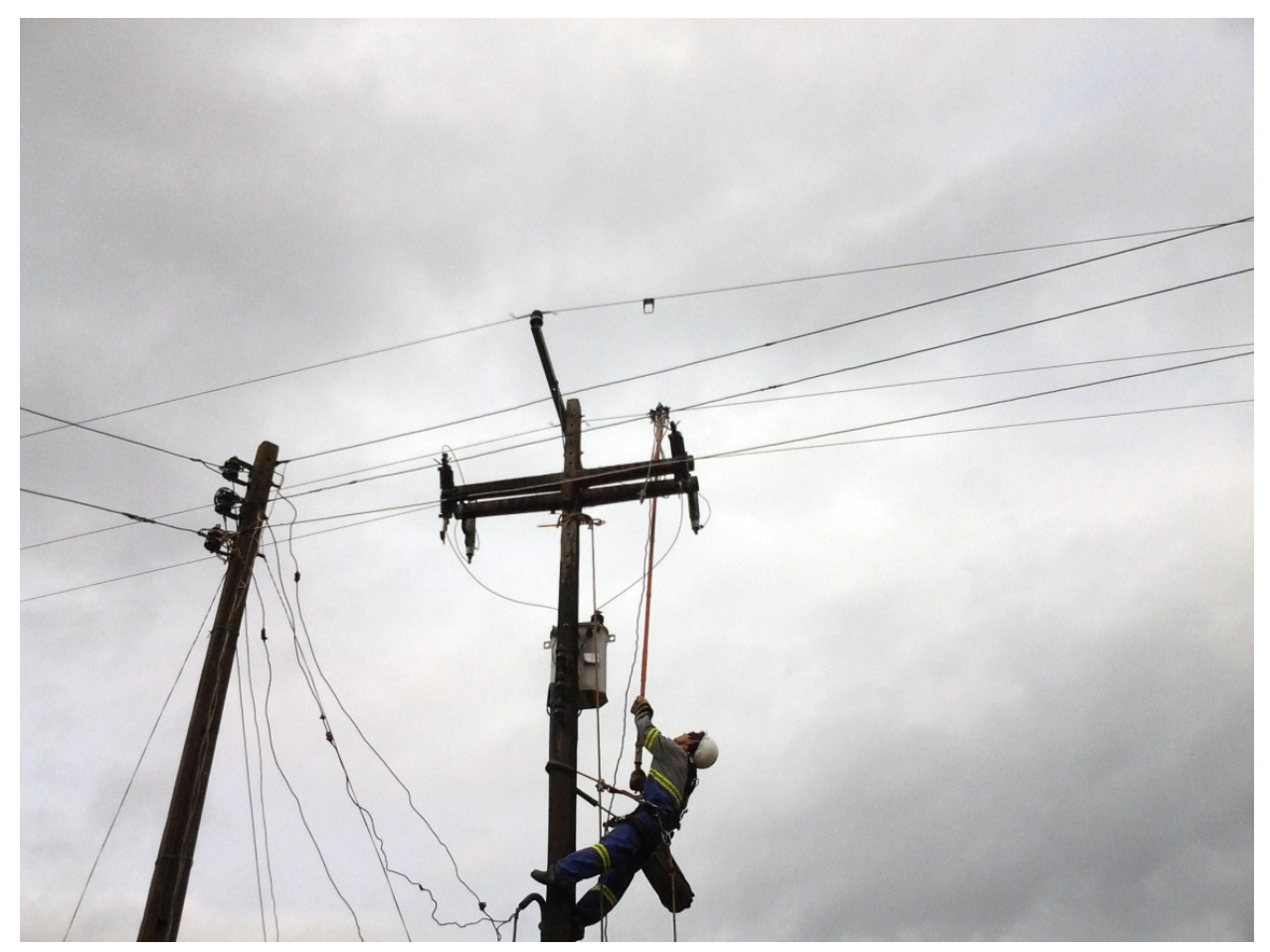

Fonte: COPEL (2015).

Nessa situação, a musculatura do pescoço é muito exigida para a sua sustentação, em função das flexões constantes que precisa realizar e das posições frequentemente assumidas pelo corpo. Esses esforços derivam do posicionamento necessário da cabeça para melhor visualização dos equipamentos manuseados e tarefa a ser executada, bem como, pela utilização dos braços em extensão, promovendo sobrecarga e tensão nos músculos e articulações dos ombros, pescoço e costas (VASCONCELOS et al., 2011).

Além dos equipamentos pesados que ele sustenta com os membros superiores, ainda há o agravante da influência de outros fatores, dependendo das condições do clima, como: o suor embaçando os óculos de segurança, a água da chuva obstruindo as lentes ou os raios solares prejudicando a visão, situações que geram ainda mais dificuldades para que ele encontre um posicionamento adequado em cima do poste.

\subsubsection{Abdução de membros superiores acima do nível dos ombros}

Atividades laborais executadas acima do nível do ombro provocam uma diminuição no fluxo sanguíneo e dos nutrientes necessários ao músculo, acarretando fadiga, dor eparestesia, e podem resultar em lesões osteomusculares na região do ombro do trabalhador (AZEVEDO; MEJIA; VALENTE, 2012). 
Podem ocorrer dores no pescoço e ombros ao se trabalhar muito tempo com os braços elevados, sem apoio. Esses problemas aparecem, principalmente, com a utilização de ferramentas manuais, de modo que, as dores se acentuam se houver emprego de forças ou execução de movimentos repetitivos com as mãos, podendo desencadear LER/DORT em casos mais graves. Se for inevitável, a tarefa realizada acima do nível dos ombros deve ser de duração limitada (DUL; WEERDMEESTER, 2004).

A Figura 7 mostra o eletricista realizando operação de chaves fusíveis com vara telescópica, atividade em que ele pratica abdução assimétrica dos membros superiores acima do nível dos ombros, sustentando o peso da vara telescópica, de aproximadamente $6 \mathrm{~kg}$, a qual foi indicada nas respostas do questionário como o segundo equipamento que mais causa dor e desconforto no manuseio (18,5\%).

Figura 7 - Abdução de braço do eletricista em operação de chave fusível.

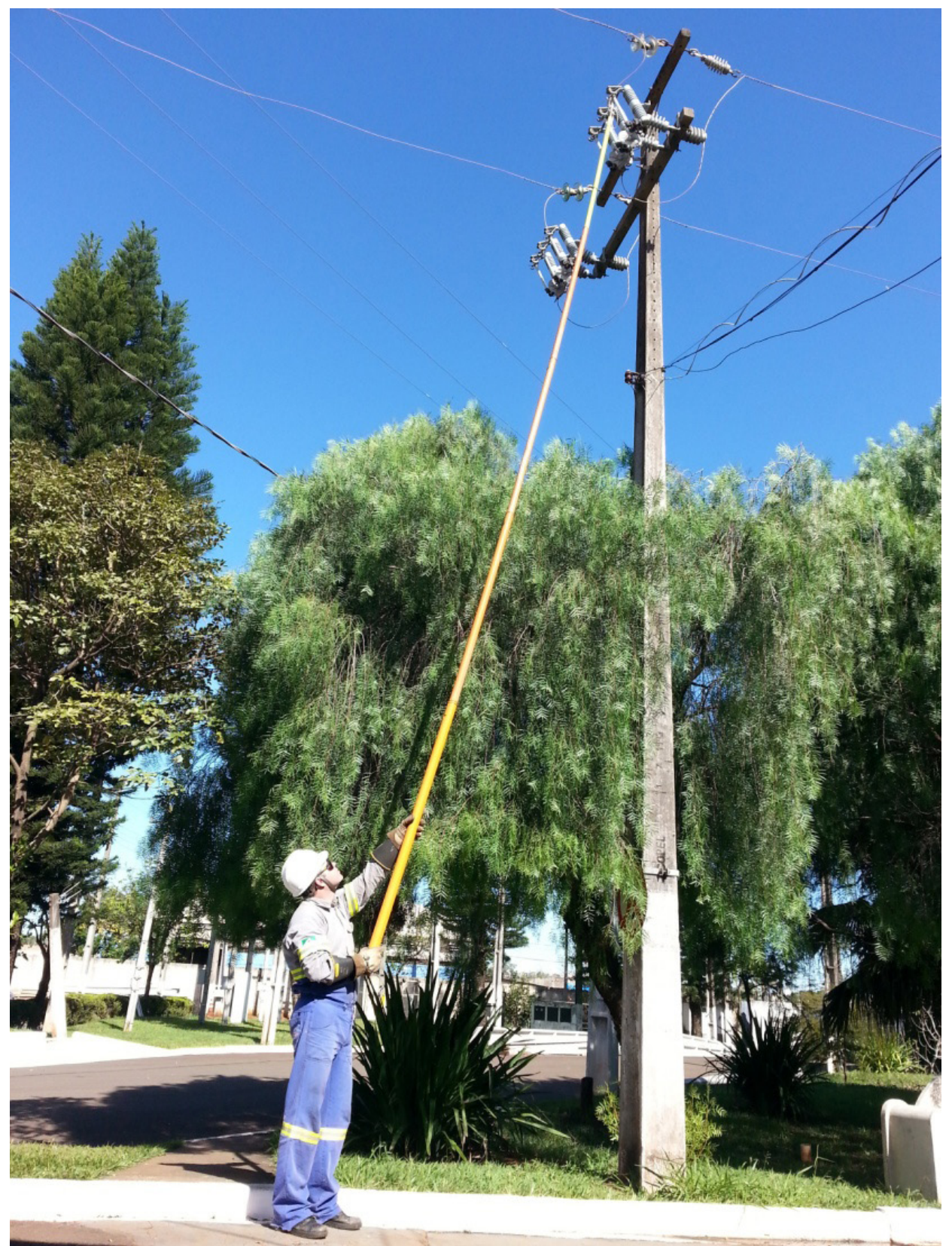

Fonte: COPEL (2015).

Projética, Londrina, v.10, n.3, p. 99-116, jul./dez. 2019 
Havendo incidência de vento, torna-se mais difícil manter o equipamento estável, totalmente estendido na vertical (cerca de 10 metros de comprimento).

\section{CONSIDERAC̄ÕES FINAIS}

Os resultados apresentados neste estudo revelaram alta quantidade de ocorrências de sintomas musculoesqueléticos entre os eletricistas da Divisão de Manutenção Norte.

Confrontando-se os dados adquiridos com as atividades executadas por estes profissionais, observadas através dos acompanhamentos em campo, pode-se associar os sintomas apresentados com as posturas, o trabalho muscular e o esforço físico exigidos para o desempenho das tarefas diárias. Essa relação justifica a implantação de medidas de intervenção ergonômica, de forma a minimizar os riscos biomecânicos existentes e evitar o agravamento das disfunções relatadas pelos sintomáticos.

Os trabalhadores envolvidos nesta pesquisa não possuem posto fixo de trabalho, que permita sua adequação às características dos trabalhadores. Dessa forma, devem ser priorizadas ações preventivas focadas em ferramentas e equipamentos, treinamentos, procedimentos de trabalho e medidas organizacionais, no intuito de reduzir a sobrecarga e prevenir o surgimento de distúrbios osteomusculares.

O controle dos riscos ergonômicos deve enfatizar principalmente as regiões dos ombros, costas e joelhos, por serem as áreas com maior predominância de sintomatologia, a qual pode prognosticar a ocorrência de DORT no futuro.

O mapeamento obtido também aponta a necessidade de condicionamento físico adequado dos empregados, objetivando o aumento de sua capacidade física nas regiões anatômicas mais requeridas para o trabalho, por meio de fortalecimentos e alongamentos, por exemplo.

Para intervenção eficiente no gerenciamento dos riscos ergonômicos, mais estudos se fazem necessários (escassos na própria literatura), para avaliação mais profunda e detalhada da exposição ergonômica presente na atividade dos eletricistas. Para tanto, sugere-se: investigar outras variáveis não exploradas nesta pesquisa, como fatores climáticos e aspectos psicológicos, capazes de interferir na condição ergonômica dos empregados; analisar as diferenciadas funções operacionais da empresa; realizar análise ergonômica das funções com profissionais especializados para tal fim, utilizando-se de protocolos e métodos de avaliação específicos. 


\section{REFERÊNCIAS}

AGUIAR, Alexandre de Paula. Agressões posturais e qualidade de vida na construção civil: um estudo multi-casos. 1996. 124 f. Dissertação (Mestrado em Engenharia de Produção) - Universidade Federal de Santa Catarina, Florianópolis, 1996.

ALENCAR, Jeronimo Farias de. LER/DORT e fibromialgia: dificuldades diagnósticas: avaliação dos sintomas musculoesqueléticos em eletricistas. 2008. 109 f. Tese (Doutorado em Fisioterapia) - Universidade Federal de São Carlos, São Carlos, 2008.

AZEVEDO, Adriana Miranda; MEJIA, Dayana Priscila Maia; VALENTE, Adriana Maria Sanches. Influência da elevação isométrica em abdução de ombro acima de $90 \circ$ em lesões osteomusculares relacionadas com atividade laboral. 2012. Monografia (Especialização em Ergonomia) - Faculdade Ávila, Goiânia, 2012.

BARROS, Eliana Nogueira Castro de; ALEXANDRE, Neusa Maria Costa. Crosscultural adaptation of the Nordic musculoskeletal questionnaire. International Nursing Review, London, v. 50, n. 2, p. 101-108, Jun. 2003.

BRASIL. Ministério da Saúde. Dor relacionada ao trabalho: lesões por esforços repetitivos (LER): distúrbios osteomusculares relacionados ao trabalho (DORT). Brasília: Ministério da Saúde, 2012.

BRASIL. Ministério da Saúde. Protocolo de investigação, diagnóstico, tratamento e prevenção de LER/DORT. Brasília: Ministério da Saúde, 2000. BRASIL. Ministério da Saúde. Saúde do trabalhador. Brasília: Ministério da Saúde, 2002. (Cadernos de Atenção Básica, n. 5).

CASTRO, Cristiane Shinohara Moriguchi de. Avaliação dos fatores de risco biomecânicos presentes na atividade ocupacional de eletricistas. 2011. $181 \mathrm{f}$. Tese (Doutorado em Fisioterapia) - Universidade Federal de São Carlos, São Carlos, 2011.

COPEL - COMPANHIA PARANAENSE DE ENERGIA. Manual de instrução técnica 161612: conjunto de aterramento temporário para redes de distribuição de baixa e média tensão. Curitiba: COPEL, 2015.

COPEL - COMPANHIA PARANAENSE DE ENERGIA. Manual de instrução técnica 161614: procedimentos de resgate e salvamento de acidentados em redes e linhas de distribuição 34,5 kV. Curitiba: COPEL, 2013.

COUTO, Hudson de Araújo. Ergonomia aplicada ao trabalho. Belo Horizonte: Ergo, 2007.

DUL, Jan; WEERDMEESTER, Bernard. Ergonomia prática. 2. ed. São Paulo: Blucher, 2004.

ENOKA, Roger Maro. Bases neuromecânicas da cinesiologia. 2. ed. São Paulo: Manole, 2000. 
FALCÃO, Franciane da Silva. Métodos de avaliação biomecânica aplicados a postos de trabalho no polo industrial de Manaus (AM): uma contribuição para o design ergonômico. 2007. Dissertação (Mestrado em Desenho Industrial) Universidade Estadual Paulista Júlio de Mesquita Filho, Bauru, 2007.

GUIMARÃES, Lia Buarque de Macedo; FISCHER, Daniela; FAÉ, Cristhiano Stefani; SALIS, Henrique Brasil; SANTOS, José Andrei Silva dos. Apreciação macroergonômica em uma concessionária de energia elétrica. In: CONGRESSO LATINO-AMERICANO DE ERGONOMIA, 7., 2002, Recife. Anais [...]. Rio de Janeiro: ABERGO, 2002. p. 1-6.

IIDA, Itiro. Ergonomia: projeto e produção. São Paulo: Blucher, 2005.

KROEMER, Karl H. E.; GRANDJEAN, Etienne. Manual de ergonomia: adaptando o trabalho ao homem. 5. ed. Porto Alegre: Bookman, 2005.

MATTOS, Ubirajara Aluízio de Oliveira; MÁSCULO, Francisco Soares (org.). Higiene e segurança do trabalho. Rio de Janeiro: Elsevier, 2011.

MOREIRA, Herivelto; CALEFFE, Luiz Gonzaga. Metodologia da pesquisa para o professor pesquisador. Rio de Janeiro: DP\&A, 2006.

RIO, Rodrigo Pires do; PIRES, Licinia. Ergonomia: fundamentos da prática ergonômica. 3. ed. São Paulo: LTR, 2001.

SEELEY, Patrícia Ann; MARKLIN, Richard William. Business case for implementing two ergonomic interventions at an electric power utility. Applied Ergonomics, London, v. 34, n. 5, p. 429-439, Sep. 2003.

VASCONCELOS, Victor Manuel de Almeida Seabra de; ZANETTE, Elaine Cristina Casagrande; SILVA FILHO, José Luiz Fonseca da; MERINO, Eugenio Andres Diaz. Diagnóstico de sintomas musculoesqueléticos em eletricistas de uma concessionária de distribuição de energia elétrica. In: CONGRESSO NACIONAL DE EXCELÊNCIA EM GESTÃO, 7., 2011, Rio de Janeiro. Anais [...]. Rio de Janeiro: UFF, 2011. p. 1-18. 